\title{
SAMBA E BALÉ CLÁSSICO NA CONSTRUÇÃO COREOGRÁFICA DE UMA PORTA-BANDEIRA: APROXIMAÇÕES COM A DANÇA IMANENTE
}

\author{
Ana Flávia Mendes \\ PPGARTES-UFPA
}

\section{Resumo}

Este texto é um relato reflexivo acerca de uma experiência artística vivida pela autora como portabandeira do Auto do Círio, cortejo cênico realizado anualmente em Belém do Pará em homenagem à Nossa Senhora de Nazaré, padroeira dos paraenses. A abordagem parte dos pressupostos da dança imanente (MENDES, 2010) para pensar sobre um processo de criação coreográfica que transita entre o samba e o balé clássico, tidos como matrizes (BIÃO, 2009) e motrizes (LIGIÉRO, 2011) da dança. A argumentação explana os agenciamentos do corpo que dança no processo criativo de uma artista-professora-pesquisa e porta-bandeira e aponta possibilidades metodológicas para o ensino e criação em dança a partir das negociações entre a dança imanente e as danças de escola de samba.

\section{Palavras-chave:}

Dança imanente; Porta-bandeira; Construção coreográfica.

\section{ARTISTA-PROFESSORA-PESQUISADORA... E PORTA-BANDEIRA}

Ser porta-bandeira é um sonho cultivado por muitas garotas nascidas no meio do samba, especialmente aquelas inseridas nas escolas de samba. Não nasci nem me criei no samba, mas durante meu trajeto artístico adotei o universo das escolas de samba como um dos meus contextos de atuação como coreógrafa. Mas, o que uma coreógrafa do campo das poéticas contemporâneas em dança faz no samba?

Quemmeconhece sabe que eu sou uma pesquisadora praticante que fala de um lugar de quem produz dança. Sou uma artista da dança. Minha atuação no mundo do samba é decorrente disto, além de ser fruto de um processo de adoção. Ainda que meus pais tivessem apreço pelas escolas de samba

\section{Abstract}

This text is a reflective account of an artistic experience lived by the author as flag bearer of the Auto do Círio, a scenic procession held annually in Belém do Pará in honor of Nossa Senhora de Nazaré, patroness of Pará's population. The approach is based on the assumptions of immanent dance (MENDES, 2010) to think about a process of choreographic creation that transits between samba and classical ballet, considered as matrices (BIÃO, 2009) and driving (LIGIÉRO, 2011). The argument explains the assemblages of the body that dances in the creative process of an artistteacher-research and flag-bearer and points out methodological possibilities for teaching and creating in dance from the negotiations between immanent dance and samba school dances.

Keywords:

Immanent dance; Flag-bearer; Choreographic creation.

e participassem dos desfiles carnavalescos de Belém como brincantes, nunca foram efetivamente comprometidos com o samba e o carnaval. Deste modo, mais do que uma descendente legítima de sambistas, sou alguém que buscou as escolas de samba por vontade própria.

“Eu nunca morei no morro, não/ Mas tenho o samba que mora em mim", diz a canção de Dimi Kireef para a trilha sonora do filme 0 samba que mora em mim, de Georgia Guerra-Peixe. Fui criada em uma região de fronteira, entre um bairro considerado nobre e outro, de periferia (Batista Campos e Jurunas, respectivamente), em Belém do Pará. Falo de uma cultura situada entre o centro e a periferia e, como pesquisadora, entre a teoria e a prática, entre o saber e o fazer, entre o empirismo e o cientificismo. Estar entre não é estar no meio de um confronto, mas num lugar de 
agenciamentos entre opostos complementares. Um lugar de potência criadora.

Sou, portanto, um corpo mediador entre centros e periferias, considerando aí toda a dimensão poética destas palavras. É deste lugar que eu venho. É deste lugar que me faço pesquisadora e pesquisa. É deste lugar que vou ao encontro do universo das escolas de samba.

Em minha trajetória carnavalesca, integrei comissões de frente nos desfiles de Belém, coreografei alas e carros alegóricos e, principalmente, fui espectadora, desde a infância, dos desfiles das escolas de samba do grupo especial do Rio de Janeiro.

Essas experiências levaram-me a cultivar grande respeito e admiração por tudo que diz respeito a uma escola de samba e, de modo especial, pelo casal de mestre-sala e porta-bandeira, os responsáveis por conduzir o símbolo maior de uma agremiação carnavalesca, isto é, seu pavilhão.

Lembro-me das brincadeiras de infância em que eu costumava realizar encenações para os membros da família. Dentre as que permanecem mais vivas em minha memória destaca-se a dança do mestre-sala e da porta-bandeira. Eu e meu irmão, com o auxílio de um cabo de vassoura e um pedaço de pano amarrado em sua ponta, fazendo referência à bandeira, costumávamos imitar os casais que apreciávamos na televisão. Talvez, quando criança, eu tenha sonhado em ser uma porta-bandeira, embora não fizesse parte, efetivamente, de uma escola de samba.

Nunca levei a brincadeira a sério, porém, como o mundo dá muitas voltas, girei, girei e fui "bailar" como docente no Programa de Pós-graduação em Artes da Universidade Federal do Pará, em que tive a felicidade de orientar dois importantes trabalhos no âmbito das danças de escola de samba em Belém. Um sobre a dança do portaestandarte, defendido em 2013 por Feliciano Marques, e outro sobre a dança do mestre-sala e da porta-bandeira, de autoria de Arianne Pimentel, defendido em 2014.

Mais ou menos no mesmo período, firmei parceria com Miguel Santa Brígida, artista-professorpesquisador tido como referencial no campo dos estudos sobre escolas de samba. A partir desta parceria, atuei como colaboradora no projeto de extensão Academia Paraense de Mestre-sala, Porta-bandeira e Porta-estandarte e aproximeime da carnavalesca, professora e pesquisadora Cláudia Palheta, cuja pesquisa de mestrado, também defendida pelo PPGARTES, tive o privilégio de avaliar como membro da banca.

No ano de 2013, ao ingressar no pós-doutorado, realizado no Programa de Pós-graduação em Artes Cênicas da Universidade Federal do Estado do Rio de Janeiro (UNIRIO), dediquei parte de minhas reflexões a experiências com a dança do mestre-sala e da porta-bandeira, vividas por mim junto à Escola de Mestre-sala, Porta-bandeira e Porta-estandarte do Rio de Janeiro, fundada por Manoel Dionísio, mestre da cultura popular formador de casais atuantes no carnaval carioca.

Além dessas experiências, coordenei, em 2014, o projeto de pesquisa Majestades do Samba e, mais recentemente, em 2015 e 2016, atuei como porta-bandeira do Auto do Círio, espetáculocortejo em homenagem à Nossa Senhora de Nazaré, padroeira dos paraenses, realizado anualmente em Belém como projeto de extensão da Universidade Federal do Pará.

Como se vê, os estudos em dança no âmbito acadêmico fizeram com que o carnaval atravessasse definitivamente a passarela do meu coração, conquistando espaço não somente como objeto de estudo, mas como práxis determinante para a compreensão do meu ser dançante. Assim, tenho dedicado parte de minha rotina à pesquisa de poéticas e processos de criação em dança, aproximando minha abordagem em dança de meus contextos de atuação artística, entre os quais se situa a dança de mestre-sala e porta-bandeira.

\section{MATRIZES E MOTRIZES DE UMA PORTA-BANDEIRA}

O casal de mestre-sala e porta-bandeira é um par que "formado por um homem e uma mulher, representa um 'casal enamorado' que carrega o principal símbolo da escola - a bandeira" (GONÇALVES, 2010, p. 19). A função da portabandeira, como o próprio nome já diz, é portar - pavilhão da agremiação carnavalesca que representa, enquanto ao mestre-sala cabe proteger este pavilhão, cortejando e zelando por sua parceira de dança. 
A dupla mantém a função dos antigos mestresala e porta-estandarte presentes nos ranchos, blocos e cordões. A dança do par, influenciada originalmente pelos minuetos e contradanças da elite, tornou-se uma espécie de balé popular com códigos e passos característicos (FERREIRA, 2004, p. 369)

Esse balé popular, nomeado por Gonçalves (2010) como "a dança nobre do carnaval", é uma invenção brasileira de matriz africana, criada pelos negros escravos que, em suas celebrações, se "inspiravam" nas danças executadas por seus senhores nos bailes de corte.

Não há como definir precisamente uma razão para a invenção desta dança, mas, particularmente, acredito que seja decorrente de uma mistura de imitação e deboche, tal como os processos de sincretismo religioso, uma vez que prevalecem, entre as contrastantes características plásticas dos movimentos, a leveza e majestade de danças europeias como o minueto e, em contrapartida, os giros e riscos característicos de danças de matriz africana e da capoeira, respectivamente, conforme argumenta Santa Brígida (2012).

É válido relembrar, nesse sentido, o conceito de matrizes estéticas proposto por Bião (2009, p. 33-34), que diz:

no âmbito geral da cultura, assim como no campo mais específico da estética, pode-se sempre buscar compreender um fenômeno contemporâneo a partir do esforço de identificação de sua filiação histórica e de seu parentesco atual com outros fenômenos. A utilização dessa expressão - matrizes estéticas, sempre no plural, possui, do ponto de vista retórico, uma consciente proposição paradoxal, posto que a palavra matriz remete à ideia de mãe, que também remete à ideia de unicidade, quando pensada como uma e única pessoa, do gênero feminino, que alimenta em seu próprio corpo e assim é explicitamente geradora de outra, enquanto a palavra matrizes multiplica esse ente, ainda que se referindo a um mesmo fenômeno - seu descendente direto. O que se pretende, ao recorrer-se a essa figura paradoxal de linguagem, é chamar a atenção para o fato de que na cultura cada fenômeno possui simultaneamente múltiplas matrizes, fruto que é de diversos processos de transculturação. (...) Assim, podemos falar, por exemplo, de matrizes estéticas, a partir de referências linguísticas, religiosas, geográficas, históricas, geo-históricas, étnicas, técnicas, temáticas, teóricas, tecnológicas etc.

Com base nas matrizes desta dança e nas experiências práticas vividas até então, tanto como observadora quanto como dançarina, vivenciei minha estreia como porta-bandeira no Auto do Círio 2015, aos 40 anos de idade. Para tanto, lancei mão de todo o aprendizado que tive na Escola de Mestre-sala, Porta-bandeira e Porta-estandarte do Rio de Janeiro e na Academia Paraense de Mestre-sala, Porta-bandeira e Porta-estandarte, agenciei informações estudadas e compartilhadas com meus orientandos de mestrado, retomei inquietações de meu projeto de pesquisa Majestades do Samba e, ainda, articulei características de dois universos aparentemente distintos, porém complementares, ambos constituintes de minha história de vida: a dança clássica e o samba.

Estudei balé clássico na Escola de Danças Clara Pinto $^{1}$ através do método inglês Royal Academy of Dancing entre os anos de 1994 e 2002. Não cheguei a concluir os chamados graus de formação, mas a experiência que tive foi bastante consistente, ao ponto de até hoje, em alguma medida, eu ainda ser reconhecida como alguém "do balé" entre meus colegas de dança.

Praticar o balé clássico não era uma tarefa muito simples, embora eu a considerasse um desafio bastante prazeroso. O auge de minha performance como dançarina clássica deu-se em 1998, quando dancei balés como o lago dos cisnes e 0 quebra nozes. Para tanto foi necessário diminuir vários números na balança. Lembro (com certo saudosismo) dos 58 centímetros de cintura atestados na fita métrica da costureira ao tomar as medidas para a confecção de um figurino. Manter as medidas e o peso em acordo com a proposta técnica e estética do balé clássico era um projeto de vida. Os quadris largos e a coxa grossa herdados dos meus ancestrais, tidos popularmente como preferência nacional dos brasileiros, não cabiam bem naquela dança. Em contrapartida, os braços finos, o pescoço comprido e os seios pouco avantajados garantiam a plasticidade desejada pelas professoras de balé, que diziam: "Da cintura pra cima tu és perfeita!".

E da cintura para baixo? Nada diziam, mas o próprio dançar e a dificuldade com o en dehors ${ }^{2}$ , tão caro para o balé clássico, revelavam que minha anatomia não era muito favorável àquela dança. Sempre fui, como os estudos sobre moda e etiqueta nomeiam, o tipo triangular, isto é, quadris mais largos que os ombros. De certa 
forma, esta sempre foi uma de minhas marcas registradas desde a infância, segundo relatos de familiares. Então, eis que surge uma frustração: eu não servia para dançar. Foi necessário um longo período para que eu compreendesse que não era bem assim, mas que, de certa forma, havia uma dança - entre tantas outras - que não me servia bem, o balé clássico. Parti, então, em busca de outras danças, em busca de uma dança que coubesse no meu corpo.

Nesta busca, o tão inadequado balé clássico passou anos escondido, até que o contato com a dança de mestre-sala e porta-bandeira ativou novamente posturas e movimentos de braços que eu julgava ter abolido de meu repertório. No encontro com o samba, reconciliei-me com o balé.

Mestre Manoel Dionísio afirma que o balé clássico pode ser muito útil a uma porta-bandeira, porém somente da cintura pra cima. $E$, se por um lado o balé clássico me cabe bem da cintura pra cima, por outro, meus quadris largos tem o potencial de garantir o equilíbrio e estabilidade necessários para portar o peso de uma fantasia de portabandeira, bem como uma bandeira presa a um mastro que deve ser sustentado pelo braço direito com a ajuda de um pequeno suporte acoplado à cintura, o chamado talabarte.

Entretanto, nem sempre tive essa compreensão. Ela só me foi de fato possível a partir do momento que vivenciei a experiência como porta-bandeira do Auto do Círio. Ao vestir pela primeira vez a saia rodada de meu traje ${ }^{3}$ e executar os primeiros giros, entendi que ali era preciso firmar os pés no chão, pensar no enraizamento, na conexão com a terra. Ao mesmo tempo, ao colocar a parte de cima do traje, um corselet ${ }^{4}$, imediatamente me projetei para o alto, adotando, deste modo, uma postura de ocupação das dimensões superior e inferior de meu corpo, por onde transitava uma energia mobilizadora que promovia a interação e integração entre o chão e o céu. Reporteime aos braços e cabeças do balé clássico, mas meus quadris, sem muito esforço, balançavam sutilmente como os de uma baiana que desce uma ladeira, garantindo o movimento e a sustentação de minha saia rodada.

Partindo dessa experiência, sublinho aqui os conceitos de "estado de corpo" e "estado de consciência" (BIÃO, 2009), compreendendo que, a partir desta experiência, alterações foram percebidas em meu ser, de modo que passei a operar de um modo distinto daquele mais habitual, numa experiência diferenciada de consciência do espaço e de mim mesma. Naquele momento materializei fisicamente, por meio das sensações percebidas, as matrizes estéticas da dança de porta-bandeira. Da cintura pra cima, uma figura da corte europeia do século XVI; da cintura pra baixo, uma negra escrava nas ladeiras do Pelourinho, em Salvador. Da cintura pra cima, matriz europeia; da cintura pra baixo, matriz africana. Da cintura pra cima, balé clássico; da cintura pra baixo, samba. Anatomia que se converte em movimento. Vida que se transforma em dança.

Essa aparente dicotomia, longe de reforçar o distanciamento cultural entre as matrizes, quer mesmo é reafirmar a interdependência entre ambas, pois é na compreensão de uma aparente divisão anatômica que, em colaboração, os referenciais africanos e europeus tornam viável a existência desta dança em mim. Esta aproximação entre "opostos" é, portanto, uma forma de mobilização do meu ser cênico dançante.

Desse modo, acredito ser possível aqui associar a noção de matriz ao conceito motriz, pois conforme esclarece Ligiéro (2011, p. 111), “o adjetivo motriz, do latim motrice de motore, que faz mover, é também substantivo, classificado como força que provoca ação, mas também uma qualidade implícita do que se move e de quem se move". Na dança de porta-bandeira por mim experimentada, as matrizes estéticas são também motrizes, isto é, foças que mobilizam minha construção coreográfica; forças sem as quais não seria possível perceber a relação de complementaridade existente entre chão e céu e, claro, entre as metades superior e inferior de minha anatomia. Sem esta compreensão não seria possível encontrar os mecanismos de construção da minha dança.

\section{DANÇA IMANENTE E A DANÇA DE MESTRE-SALA E PORTA-BANDEIRA}

Vivenciar a dança de mestre-sala e portabandeira no Auto do Círio não é uma experiência artística que se encerra com a encenação. Pelo 
contrário, a encenação é apenas a passagem por uma etapa de algo que já vem sendo construído em minha práxis como artista-professorapesquisadora. Dançar como porta-bandeira é o toque que faltava para reforçar meu argumento de que a dança não está desvinculada do corpo que dança; ela reflete o próprio corpo que dança. E mais, assim como qualquer corpo pode dançar, qualquer coisa pode vir a ser dança.

No tocante à dança de mestre-sala e portabandeira, a particularidade de quem dança é o componente diferencial, aquilo que distingue e dá notoriedade a um casal. Arianne Pimentel, em sua pesquisa de mestrado, defende a existência de uma dança autoral na medida em que, ser mestre-sala e porta-bandeira requer de quem dança a criação de um estilo pessoal, ou, como aponta Gonçalves (2010), um estilo próprio.

Seja pelo estilo próprio, seja pela dança autoral, o que me instiga diante da dança de mestre-sala e porta-bandeira é o fato de estar diante de um saber transmitido pelas vias da cópia e repetição, mas que não se sustenta na imitação restrita daquilo que se copia. Sinto-me diante de uma contradição verdadeiramente mobilizadora para a concepção de dança por mim desenvolvida, a qual denomino dança imanente.

Desde a realização de minha pesquisa de doutorado tenho argumentado acerca da existência da dança imanente como práxis que prima pela autonomia do corpo dançante. A partir deste pensamento-fazer procuro incentivar dançarinos a se colocarem no movimento. Não parto de vocabulários de movimento existentes a priori e, portanto, não ensino este ou aquele "passo de dança", mas oriento a pesquisa de movimentos, instigo e contribuo na edição do material desenvolvido, recortando e colando peças de movimento até formar, em parceria com o dançarino, a coreografia que ele irá executar. Deste modo, busco instigar em meus alunos/ dançarinos a construção de vocabulários que, inevitavelmente, tem relação com suas histórias de vida e experiências de movimento anteriores, sejam elas provenientes de gêneros de dança ou não. Assim, na dança imanente não importa a procedência do vocabulário de movimentos de quem dança, mas como este é manuseado na criação e execução de uma dança.
Articulada à noção de imanência e plano de imanência em Deleuze e Guattari (1992), a dança imanente vale-se das particularidades e histórias de vida de quem a dança e, logo, é construída pelos seus próprios praticantes, tidos, portanto, como matéria-prima para a criação artística. Não há, nesta perspectiva, uma técnica de dança préestabelecida, mas sim uma construção técnica dada a partir de estímulos gerados pelo coreógrafo, os quais podem advir ou não de padrões técnicocorporais pré-existentes em dança. (...). A criação do movimento a ser dançado é como uma coleta de dados que, após selecionados individualmente por cada dançarino, são compartilhados e editados naquilo que se torna a coreografia. Trata-se, portanto, de um fazer que se constroi coletivamente, refletindo a interdependência dos participantes no processo de criação (MENDES, 2014, pp. 7-8).

A dança imanente enquanto práxis cênica é, então, uma construção e, deste modo, ela é também uma proposição metodológica para o ensino e criação em dança. Ela não existe previamente enquanto técnica de dança, como o balé clássico ou outros gêneros de dança já consolidados. Ela é uma dança sem gênero, embora tenha inspiração em princípios da pós-modernidade coreográfica, como a multiplicidade e a liberdade de criação (SILVA, 2005). É uma dança devir (DELEUZE, 1992), uma potência do corpo que dança, extraída a partir de um procedimento coreográfico a que chamo "dissecação artística do corpo" (MENDES, 2010). Nesta perspectiva, a dança imanente materializa-se na medida em que dançarino e coreógrafo empenham-se em agir conjuntamente em prol de uma invenção coreográfica.

Quando formulei este pensamento-fazer em dança não me importei em chegar a um lugar em que determinados movimentos obrigatórios precisassem ser aprendidos e, por fim, dançados, haja vista que a dança, em minha concepção, pode vir de qualquer lugar. As vivências com a dança de mestre-sala e porta-bandeira, contudo, colocam-me diante da lida simultânea com o paradoxo há pouco referido, isto é, a necessidade de estar atenta à pré-existência de um vocabulário de movimentos obrigatórios composto de giros, cortejos e riscados, entre outros, e a liberdade de manusear estes em situações de ensino e aprendizagem de um gênero de dança específico.

Ao aproximar a dança de mestre-sala e portabandeira da dança imanente verifico, sobretudo na questão da autonomia, valores e princípios 
semelhantes no fazer metodológico. A noção de estilo, tão prezada pelos praticantes da dança de mestre-sala e porta-bandeira, assemelha-se sobremaneira a ideia de movimento autônomo (MENDES, 2010), comum à dança imanente. $\mathrm{Na}$ dança imanente, o dançarino, também chamado de intérprete-criador, é incentivado a desenvolver autonomamente a criação de seu repertório de movimentos, o qual poderá ou não tornarse coletivo, a depender do processo de criação. $\mathrm{Na}$ dança de mestre-sala e porta-bandeira a noção de estilo está ligada não exatamente a criação de um repertório de movimentos, mas a execução de um repertório pré-existente, o qual é mais ou menos dado aos bailantes desta dança. Instiga-me pensar como a ideia de uma dada sistematização em dança funcionaria na práxis da dança imanente, se é que já não funciona, em alguma medida.

Partindo desta reflexão e ponderando as experiências vividas em minha lida artística, especialmente como porta-bandeira do Auto do Círio, observo que copiar e repetir não são ações fortuitas em que o dançarino precisa, como uma máquina, reproduzir de forma exata aquilo que Ihe é solicitado. Admito que por muito tempo, após afastar-me do balé clássico, tive preconceito com metodologias de ensino da dança pautadas em estratégias de cópia e repetição. Acreditava que o estímulo à autonomia criativa do dançarino apenas pudesse ser dado a partir de estratégias metodológicas que the permitissem inventar coisas novas.

Contudo, ao vivenciar a dança de mestre-sala e porta-bandeira entendo mais claramente de que maneira a invenção articula-se à história de vida, ainda que haja um repertório gestual a ser executado. Não falo da invenção de passos ou movimentos diferentes e fora dos padrões exigidos pela dança, mas da invenção do meu próprio modo de dançar estes padrões (estilo pessoal ou estilo próprio), o que, a meu ver, pode ser aplicado a qualquer gênero de dança, sendo a compreensão e autoconhecimento da anatomia um dos caminhos possíveis para agenciar a história de vida de quem dança à sua criação em dança.

Nesse sentido, é pertinente não somente investigar os elementos históricos da vida de quem dança, mas encontrar estratégias de mobilização destes no sentido de construir a dança para a cena. No caso da experiência aqui refletida, esta mobilização se dá pelo reconhecimento estrutural da anatomia de uma porta-bandeira. Contudo, este reconhecimento não pode ser a atividade fim do processo de criação. Ele é apenas o disparo deste processo, e deve ser manuseado pelo corpo para criar outro corpo: o corpo que dança.

Em meu processo particular, a compreensão da anatomia é imageticamente traduzida na relação corpo e espaço, chão e céu, a qual é, também, uma espécie de metáfora das matrizes africana e europeia, próprias da dança. Entretanto, esta mesma metáfora é o que me dá a esperada diferenciação nos estados de corpo e consciência na medida em que encontro, nas matrizes, as motrizes para a apropriação de mim mesma na execução do repertório de movimentos comuns à dança. Assim, o estilo próprio, aquilo que distingue uma porta-bandeira, encontrase na própria construção coreográfica, pois a assinatura pessoal é criada na relação entre as matrizes estéticas da dança e a minha anatomia.

É claro que não espero, com isto, apontar uma fórmula para encontrar o estilo próprio de qualquer porta-bandeira. Não se trata de uma receita para tal. Este foi o modo como agenciei estratégias para a criação de meu estilo próprio ao atuar como porta-bandeira do Auto do Círio. Neste sentido, é válido ressaltar que o Auto do Círio não é uma escola de samba. Embora congregue uma comunidade de artistas que, juntos, caminham em cortejo embalados por samba e enredo específico, não se caracteriza como um desfile carnavalesco, mas como prática espetacular embalada pelo carnaval, pelo teatro de rua e pela religiosidade. Isto significa que, apesar de eu já ser uma porta-bandeira, ainda não sou porta-bandeira de uma escola de samba. Mais uma vez, aqui, reconheço meu lugar de agenciadora, mediadora entre matrizes. Nem bailarina clássica, nem sambista, porta-bandeira. Nem espetáculo, nem carnaval, Auto do Círio. Nem dança imanente, nem dança de mestre-sala e porta-bandeira, dança de mestre-sala e portabandeira do/no Auto do Círio.

Os desdobramentos da problemática parecem infindáveis, o que os torna ainda mais envolventes. Particularmente, como artista-professora- 
pesquisadora, minha intenção é apresentar essas reflexões como um modo de pensar sobre uma abordagem metodológica possível em dança. Trata-se de uma possibilidade não apenas para o ensino e aprendizagem da própria dança de mestre-sala e porta-bandeira, mas talvez sirva como abertura para outras experiências de criação coreográfica, independentemente de gêneros de dança, mas comprometidas com a história de vida de quem dança, tal como proponho na práxis da dança imanente.

De todo modo, estas elucubrações, partindo de uma experiência vivida por mim como portabandeira, me fazem compreender que a dança, a minha dança, não é tão rigorosa quanto um exame da Royal Academy ${ }^{5}$, nem tão ansiosa por liberdade como os movimentos de Isadora Duncan ${ }^{6}$. Danço a disciplina do balé clássico e o desprendimento de uma sessão de contato-improvisação ${ }^{7}$. Danço uma dança de giros que renovam o ir e vir da minha existência e a minha resistência. Danço o amor, danço o samba, danço a fé. Hoje sou uma porta-bandeira e danço a minha própria vida.

\section{NOTAS}

1. Clara Pinto é uma personalidade da dança paraense. Fundadora da escola que leva seu nome, atua no mercado desde os anos 1970.

2. Posição de rotação externa que vai da articulação do quadril aos tornozelos e que se caracteriza como princípio elementar para a dança clássica, conferindo às bailarinas a popular posição de pés "dez pras duas", isto é, pés voltados para fora, lembrando a posição dos ponteiros de um relógio ao marcar 13 horas e 50 minutos.

3. Meu traje de porta-bandeira, assim como o de meu mestre-sala, Ercy Souza, foram idealizados pela carnavalesca Cláudia Palheta e executados por outras duas pessoas. Curiosamente, a saia foi confeccionada por um negro, chamado Marco Antônia Alcântara, carnavalesco atuante em Belém e a parte de cima, pelo estilista Ney Lopes, especializado em confeccionar vestidos de baile para mulheres. Considero que o traje tenha sido de fundamental importância para despertar o reconhecimento e compreensão das matrizes estéticas da dança.
4. Cinta modeladora que lembra os trajes da corte europeia.

5. Royal Academy of Dancing é um método inglês de ensino do balé clássico adotado por várias escolas de dança do mundo. Anualmente os alunos são submetidos a exames, pois o curso prevê a transição de níveis, dos básicos aos mais avançados.

6. Pioneira da dança moderna que preconizava o ideal de liberdade em contraposição à rigidez do ballet clássico.

7. Técnica de movimento que opera com a improvisação a partir do contato entre corpos.

\section{REFERÊNCIAS}

BIÃO, Armindo Jorge de Carvalho. Etnocenologia e a cena baiana: textos reunidos. Salvador: $P \& A$ Gráfica e Editora, 2009.

DELEUZE, Gilles e GUATTARI, Felix. 0 que é a filosofia?. São Paulo: Editora 34, 1992.

FERREIRA, Felipe. 0 livro de ouro do carnaval brasileiro. Rio de Janeiro: Ediouro, 2004.

GONÇALVES, Renata de Sá.. A dança nobre do carnaval. Rio de Janeiro: Aeroplano, 2010.

LIGIÉRO, Zeca. Corpo a corpo: estudo das performances brasileiras. Rio de Janeiro: Garamond, 2011.

MENDES, Ana Flávia. Dança imanente: uma dissecação artística do corpo no processo de criação do espetáculo Avesso. São Paulo: Escrituras, 2010.

SANTA BRÍGIDA, Miguel. o sagrado sorrizo de Selmynha: a dança do mestre-sala e da portabandeira na cena afro-carioca. Repertório, Salvador, n) 19, p.18-25, 2012.2. UFBA, 2012. 


\section{SOBRE A AUTORA}

Ana Flávia Mendes Sapucahy é artista-professorapesquisadora. Pós-doutora em Artes Cênicas (PPGAC - UNIRIO). Doutora e Mestra em Artes Cênicas (PPGAC-UFBA). ProfessoradaUniversidade Federal do Pará (Instituto de Ciências da Arte/ PPGARTES/ Escola de Teatro e Daça). Fundadora e diretora artística da Companhia Moderno de Dança. Autora dos livros: Gesto transfigurado; Dança imanente e $A$ dança imanente no ensino e criação em artes cênicas. Organizadora dos livros: Abordagens criativas na cena e Ensaios de uma Companhia (Pós)Moderno de Dança. Coordena o grupo de pesquisa Coreoepistemologias. Foi contemplada com o Prêmio FUNARTE de Dança Klauss Vianna em 2006, 2008, 2009, 2011, 2013 e 2015, com a Bolsa de Produção Crítica em Artes da FUNARTE em 2008 e com a Bolsa de Pesquisa, Experimentação e Criação Artística do Instituto de Artes do Pará em 2010. Possui experiência na área de Artes, com ênfase em Artes Cênicas, atuando principalmente no campo das poéticas em dança. Contato: anaflaviadanca@gmail.com 